\title{
Procedural, In-Hospital and One Year Follow-Up Outcome of Success versus Failure Percutaneous Coronary Intervention in Chronic Total Occlusions
}

\author{
Dr. Suresh V Patted ${ }^{1}$, Dr. Prabhu C Halkati², Dr. Vishwanath Hesarur ${ }^{3}$, Dr. Sanjay C Porwal ${ }^{4}$, \\ Dr. Sameer Ambar ${ }^{5}$, Dr. Ameet Sattur ${ }^{6}$
}

\begin{abstract}
Introduction: Percutaneous coronary intervention (PCI) of chronic total occlusion (CTO) lesions are the most technically challenging for the interventional cardiologist with lower procedural success rates and higher complications. However, there are controversy in short-term and long-term results. Aims and Objectives: The purpose of this study was to know the procedural success rate, in-hospital and 1 year follow-up outcome of successful versus failure PCI in CTO. Material and Methods: This single center, observational study was conducted at KLEs Dr Prabhakar Kore Hospital \& MRC, Belgaum, Karnataka, India, from January 2013 to September 2014. A total of 101 consecutive CTO patients in whom PCI was attempted were included in the study. Detailed clinical, angiographic, procedural, in-hospital and 1 year follow-up outcome data were collected and compared success versus failed procedures. Results: Procedural success rate was seen in 79 patients (78.21\%). Patients with failed CTO-PCI compared to success group had a higher incidence of diabetes mellitus $(72.73 \%$ vs. $54.43 \%$; $p=0.14)$, smoking $(54.55 \%$ vs. $41.77 \%$; $p=0.33)$, prior myocardial infarction (MI) (68.18\% vs. $41.77 \% ; p=0.03)$ and multivessel involvement $(13.6 \%$ vs. $8.86 \% ; p=0.53)$. In-hospital major adverse cardiac events (MACE) rate was significantly higher in failed CTO-PCI (31.82 \% vs.0\%; $=0.00)$ patients. When followed-up for 1 year, failed CTOPCI was significantly associated with higher rate of 1 year MACE (57.14\% vs. 18.99\%;p=0.00), especially revascularization (33.33\% vs. 12.66\%; death, MI and need of CABG compared to failed CTO-PCI
\end{abstract}

Keywords: Percutaneous coronary intervention (PCI), chronic total occlusion (CTO), major adverse cardiac events (MACE), myocardial infarction $(\mathrm{MI})$, coronary artery bypass grafting (CABG).

\section{Introduction}

Coronary Chronic total occlusion's (CTO) are commonly encountered complex lesions identified in $15 \%$ to $30 \%$ of all patients referred for coronary angiography $(\mathrm{CAG})^{1,2}$ and attempted only in $10 \%$ of patients undergoing percutaneous coronary intervention (PCI). ${ }^{3-5}$ These lesions are the most technically challenging for the interventional cardiologist with lower procedural success rates and higher complications. Because of these reasons, CTO's are commonly referred for coronary artery bypass grafting $(\mathrm{CABG})$ or managed medically. Although the duration of occlusion is difficult to determine on clinical grounds, a total occlusion must be present for atleast 3 months to be considered a true CTO. ${ }^{6}$

The technical and procedural success rates of CTO-PCI have steadily increased over last 15 years because of greater operator experience, improvement in equipment and procedural Techniques. ${ }^{7,8}$ However, there is limited data on procedural and in-hospital outcome after PCI of CTO. Several previous studies have shown procedural success rates and outcomes after CTO-PCI, but they have included patients with occlusion of 4 weeks duration. ${ }^{9,10,11}$ The present study was undertaken to know the procedural, in-hospital and 1 year follow-up outcome of successful versus failure $\mathrm{PCI}$ in true CTO's.

\section{Material And Methods}

Study design: This single center, retrospective, observational clinical study was conducted at KLEs Dr Prabhakar Kore Hospital \& MRC, Belgaum, Karnataka, India, from January 2013 to September 2014. A total of 101 consecutive CTO patients in whom PCI was attempted were included in the study. The study was approved by the institutional ethics committee.

Patients with acute myocardial infarction (AMI) or occlusion of culprit vessel $<30$ days, severe hepatic dysfunction or contraindications to antiplatelets were excluded from the study.

CTO was defined as a lesion with TIMI (Thrombolysis in myocardial infarction) 0 or 1 flow with a total duration of $>3$ months. ${ }^{6}$ Estimation of occlusion duration was based on a history of first onset of angina, a history of MI in the target vessel territory or comparision with a previous angiogram.

A technical success was defined as the ability to cross the occluded segment with both a wire and balloon and successfully open the artery with a $<40 \%$ residual stenosis in all views. Procedural success was defined an a technical success with no in-hospital major adverse cardiac events (MACE) with TIMI 3 flow. A CTO success was defined as a technical success

A MACE was defined as the occurrence of death, Myocardial Infarction (MI) or urgent revascularization during the same admission. ${ }^{12}$ Stent thrombosis was defined according to academic research consortium. ${ }^{12}$

All patients underwent antegrade approach via femoral route.

Dual injection was performed through selective coronary angiography (CAG) for the CTO-PCI target vessel and through another vessel ( the contralateral coronay artey or a 


\section{International Journal of Science and Research (IJSR) \\ ISSN (Online): 2319-7064 \\ Index Copernicus Value (2013): 6.14 | Impact Factor (2014): 5.611}

bypass graft) that provides collaterals to the distal vessel and determining the lesion length. The guidewire strategies used were single wire and parallel wire technique. Angioplasty was performed using standard over the wire technique and coronary guide wires with progressive wire tip stiffness were used.

All patients were pretreated with aspirin ( $325 \mathrm{mg}$ ) and clopidogrel ( a loading dose of $300 \mathrm{mg}$ at least 6 hours before procedure). After the procedure, all patients were given aspirin $150 \mathrm{mg}$ OD indefinitely and clopidogrel $75 \mathrm{mg}$ twice daily for first 24 months followed by $75 \mathrm{mg}$ indefinitely after implantation of stents. ${ }^{13,14}$ Glycoprotein II $\mathrm{b} /$ IIIa inhibitors were given at the discretion of the operator. Unfractionated heparin (100 U/kg bolus ) with additional administration if necessary to achieve an ACT $\geq 250$ seconds .

Patients were divided into two groups with regard to the success or failure to achieve revascularization of the occluded artery.

All patients baseline demographic, clinical, procedural characteristics and in-hospital outcomes were recorded. Clinical follow up was performed in all patients at 1, 3, 9 \& 12 months post procedure. All patients post procedural ECG were routinely assessed for presence of new $\mathrm{Q}$ waves.
Patients who had angina underwent treadmill test (TMT). Follow up CAG was done in patients with positive TMT or patients who complained of recurrent chest pain . Study end points were MACE including death, MI, revascularization (TVR and TLR) and stent thrombosis .

Statistical analysis: Continuous data are presented as mean $\pm \mathrm{SD}$ and differences are compared using student $t$ test. Discrete variables are expressed as counts and percentages. In two-by-two tables, differences were assessed by Fisher exact test. In two-by-three and two by four tables, differences were assessed by Chi-square test. All statistical tests were two-tailed. All statistical calculations were performed with minitab 15 and SPSS version 17 statistical software. A p value of 0.05 or less was considered significant.

\section{Results}

Between January 2013 to September 2014, a total of 101 patients underwent attempted PCI of CTOs. In 79 patients (78.21\%), procedural success was achieved and 22 patients $(21.78 \%)$ remained unsuccessful. Baseline demographics for both CTO success and failure group are shown in Table 1.

Table 1: Baseline Demographics

\begin{tabular}{|c|c|c|c|c|}
\hline & $\begin{array}{c}\text { Total } \\
(\mathrm{n}=101)\end{array}$ & $\begin{array}{c}\text { CTO Success } \\
(\mathrm{n}=79)\end{array}$ & $\begin{array}{c}\text { CTO Failure } \\
(\mathrm{n}=22)\end{array}$ & P Value \\
\hline Variable & $57.06 \pm 8.69$ & $56.63 \pm 9.11$ & $58.59 \pm 6.99$ & $0.353^{\mathrm{NS}}$ \\
\hline Age(years) & $80(79.21)$ & $64(81.01)$ & $16(72.73)$ & $0.397^{\mathrm{NS}}$ \\
\hline Male gender & $90(89.11)$ & $69(87.34)$ & $21(95.45)$ & $0.448^{\mathrm{NS}}$ \\
\hline Angina & $45.39 \pm 3.44$ & $45.69 \pm 3.81$ & $44.67 \pm 2.29$ & $0.336^{\mathrm{NS}}$ \\
\hline Ejection Fraction (\%) & $59(58.42)$ & $43(54.43)$ & $16(72.73)$ & $0.147^{\mathrm{NS}}$ \\
\hline Diabetes Mellitus & $66(65.35)$ & $53(67.09)$ & $13(59.09)$ & $0.613^{\mathrm{NS}}$ \\
\hline Hypertension & $63(62.38)$ & $50(63.29)$ & $13(59.09)$ & $0.805^{\mathrm{NS}}$ \\
\hline Dyslipidemia & $31(30.69)$ & $26(32.91)$ & $5(22.73)$ & $0.440^{\mathrm{NS}}$ \\
\hline Obesity & $45(44.55)$ & $33(41.77)$ & $12(54.55)$ & $0.337^{\mathrm{NS}}$ \\
\hline Smoking & $27(26.73)$ & $24(30.38)$ & $3(13.64)$ & $0.296^{\mathrm{NS}}$ \\
\hline Family History Of CAD & $7(6.93)$ & $7(8.86)$ & $0(0.00)$ & $0.342^{\mathrm{NS}}$ \\
\hline CVA & $3(2.97)$ & $3(3.80)$ & $0(0.00)$ & $1.000^{\mathrm{NS}}$ \\
\hline PVD & $48(47.52)$ & $33(41.77)$ & $15(68.18)$ & $0.033^{*}$ \\
\hline Prior MI & $17(16.83)$ & $17(21.52)$ & $0(0.00)$ & $0.020^{*}$ \\
\hline Prior PCI & $3(2.97)$ & $2(2.53)$ & $1(4.55)$ & $0.525^{\mathrm{NS}}$ \\
\hline
\end{tabular}

Data listed as number of patients (percent of group), mean \pm SD.

Mean age and gender frequency were similar in both groups. Anginal chest pain was the predominant presenting symptom in both groups. The CTO failure group had higher incidence of diabetes (DM) (72.73\%), smoking (54.55\%) and prior MI (68.18\%) and CTO success group had higher incidence of prior PCI. Baseline angiographic characteristics for both groups are shown in Table 2 .

Table 2: Baseline Angiographic Characteristics

\begin{tabular}{|l|c|c|c|c|}
\hline Variable & $\begin{array}{c}\text { Total } \\
(n=101)\end{array}$ & $\begin{array}{c}\text { CTO } \\
\text { Success } \\
(n=79)\end{array}$ & $\begin{array}{c}\text { CTO } \\
\text { Failure } \\
(n=22)\end{array}$ & P Value \\
\hline No. Of Diseased Vessels \\
\cline { 1 - 4 } SVD & $64(63.37)$ & $49(62.03)$ & $15(68.18)$ & $0.530^{\mathrm{NS}}$ \\
\cline { 1 - 4 } DVD & $27(26.73)$ & $23(29.11)$ & $4(18.18)$ & \\
\hline TVD & $10(9.90)$ & $7(8.86)$ & $3(13.64)$ & \\
\hline
\end{tabular}

\begin{tabular}{|c|c|c|c|c|}
\hline \multicolumn{5}{|c|}{ CTO-Location } \\
\hline LM & $0(0.00)$ & $0(0.00)$ & $0(0.00)$ & \multirow[t]{4}{*}{$0.219^{\mathrm{NS}}$} \\
\hline LAD & $53(52.48)$ & $45(56.96)$ & $8(36.36)$ & \\
\hline $\mathrm{RCA}$ & $39(38.61)$ & $28(35.44)$ & $11(50.0)$ & \\
\hline LCX & $9(8.91)$ & $6(7.59)$ & $3(13.64)$ & \\
\hline \multicolumn{5}{|c|}{ Collateral Filling } \\
\hline $\begin{array}{l}\text { Bridge } \\
\text { Collaterals }\end{array}$ & $30(29.70)$ & $22(27.85)$ & $8(36.36)$ & \multirow[t]{2}{*}{$0.439^{\mathrm{NS}}$} \\
\hline $\begin{array}{l}\text { Retrograde } \\
\text { Filling }\end{array}$ & $71(70.30)$ & $57(72.15)$ & $14(63.64)$ & \\
\hline \multicolumn{5}{|l|}{ TIMI Flow } \\
\hline Grade 0 & $79(78.22)$ & $61(77.22)$ & 18(81.82) & \multirow[t]{2}{*}{$0.644^{\mathrm{NS}}$} \\
\hline Grade 1 & $22(21.78)$ & $18(22.78)$ & $4(18.18)$ & \\
\hline
\end{tabular}

Data listed as number of patients (percent of group).

The CTO failure group had higher incidence of triple vessel disease (TVD), bridging collaterals and TIMI grade 0 flow. 


\section{International Journal of Science and Research (IJSR) \\ ISSN (Online): 2319-7064 \\ Index Copernicus Value (2013): 6.14 | Impact Factor (2014): 5.611}

The CTO was located predominantly in left anterior descending (LAD) coronary artery (52.48\%), followed by right coronary artery (RCA)(38.61\%) and left circumflex coronary artery $(\mathrm{LCX})(8.91 \%)$. The CTO was located predominantly in the RCA (50\%) in CTO failure group and LAD (56.96\%) in success group. The overall technical and procedural success rates were $79.20 \%$ and $78.21 \%$ for the total CTO cohort. Among the failed procedures, inability to cross the lesion with a guide wire and perforation were the main reasons for failure in $81.82 \%(18)$ and $18.18 \%(4)$ of cases.(Figure 1)

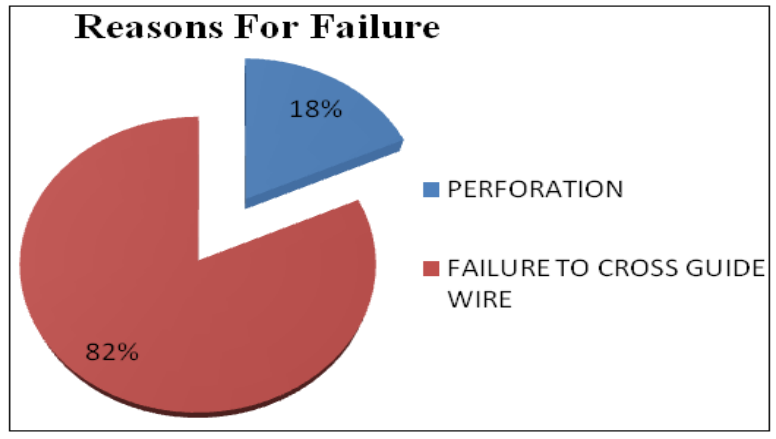

Figure 1: Reasons for failure

Guide wires and guide support used are shown in Table 3.
Table 3: Procedural Characteristics- Guide wires and Guide Support

\begin{tabular}{|c|c|c|c|c|}
\hline Variable & $\begin{array}{c}\text { Total } \\
(n=101)\end{array}$ & $\begin{array}{c}\text { CTO } \\
\text { Success } \\
(n=79) \\
\end{array}$ & $\begin{array}{c}\text { CTO } \\
\text { Failure } \\
(n=22)\end{array}$ & $P$ Value \\
\hline Procedure Success & $101(100.00)$ & $79(78.21)$ & $22(21.78)$ & $0.042 *$ \\
\hline \multicolumn{5}{|l|}{ Guide Wires } \\
\hline Miracle 6 & $17(16.83)$ & $9(11.39)$ & $8(36.36)$ & \multirow[t]{6}{*}{ NA } \\
\hline Conquest Pro & $17(16.83)$ & $15(18.99)$ & $2(9.09)$ & \\
\hline Whisper & $19(18.81)$ & $16(20.25)$ & $3(13.64)$ & \\
\hline Fielder XT & $32(31.68)$ & $27(34.18)$ & $5(22.73)$ & \\
\hline Fielder Fc & $3(2.97)$ & $3(3.80)$ & $0(0.00)$ & \\
\hline Cross It $100 \mathrm{XT}$ & $13(12.87)$ & $9(11.39)$ & $4(18.18)$ & \\
\hline \multicolumn{5}{|l|}{ Guide Support } \\
\hline Microcatheter & $61(60.40)$ & $43(54.43)$ & $18(81.82)$ & \multirow[t]{3}{*}{$0.005^{* *}$} \\
\hline Balloon Support & $33(32.67)$ & $32(40.51)$ & $1(4.55)$ & \\
\hline Tornus & $7(6.93)$ & $4(5.06)$ & $3(13.64)$ & \\
\hline
\end{tabular}

Data listed as number of patients (percent of group).

Fielder XT guide wire (34.18\%) was the most successful guide wire in crossing the CTO followed by whisper wire $(20.25 \%)$ and conquest Pro wire $(18.99 \%)$ supported by microcatheter $(54.43 \%)$ and balloon $(40.51 \%)$. Stent used are shown in Table 4.

Table 4: Procedural Characteristics - Stent Used

\begin{tabular}{|l|l|l|l|}
\hline \multicolumn{1}{|c|}{ Variable } & \multicolumn{1}{|c|}{$\begin{array}{c}\text { Total } \\
(n=101)\end{array}$} & $\begin{array}{c}\text { CTO } \\
\text { Success } \\
(n=79)\end{array}$ & $\begin{array}{c}\text { CTO } \\
\text { Failure } \\
(n=22)\end{array}$ \\
\hline Stent Used & \multicolumn{3}{|l|}{} \\
\hline Drug Eluting Stent (DES) & $75(74.25)$ & $75(94.93)$ & $0(0.00)$ \\
\hline Sirolimus (SES) & $52(51.49)$ & $52(65.82)$ & $0(0.00)$ \\
\hline Everolimus (EES) & $18(17.82)$ & $18(22.78)$ & $0(0.00)$ \\
\hline Zotarolimus (ZES) & $5(4.95)$ & $5(6.33)$ & $0(0.00)$ \\
\hline Baremetal Stent (BMS) & $4(3.96)$ & $4(5.06)$ & $0(0.00)$ \\
\hline No. Of Stents Per Lesion & $1.16 \pm 0.80$ & $1.48 \pm 0.57$ & $0.00 \pm 0.00$ \\
\hline Stent Length (mm) & $22.14 \pm 13.16$ & $28.30 \pm 6.74$ & $0.00 \pm 0.00$ \\
\hline Stent Diameter (mm) & $2.41 \pm 1.31$ & $3.09 \pm 0.29$ & $0.00 \pm 0.00$ \\
\hline
\end{tabular}

Data listed as number of patients (percent of group), mean \pm SD.

Stents were implanted in all CTO success group with Drug eluting stent (DES) in $94.93 \%$ [ Sirolimus eluting stent (SES) $-65.82 \%$, Everolimus eluting stent (EES)- $22.38 \%$ and zotarolimus eluting stent (ZES) - $6.33 \%$ ] and Baremetal stent (BMS) in $5.66 \%$ of cases . Mean stent per lesion was $1.48 \pm 0.57 \mathrm{~mm}$ with $28.30 \pm 6.74 \mathrm{~mm}$ in length and $3.09 \pm 0.29 \mathrm{~mm}$ in diameter. Procedure time (min), fluoroscopy time ( $\mathrm{min}$ ) and contrast dose (ml) are shown in Figure 2.

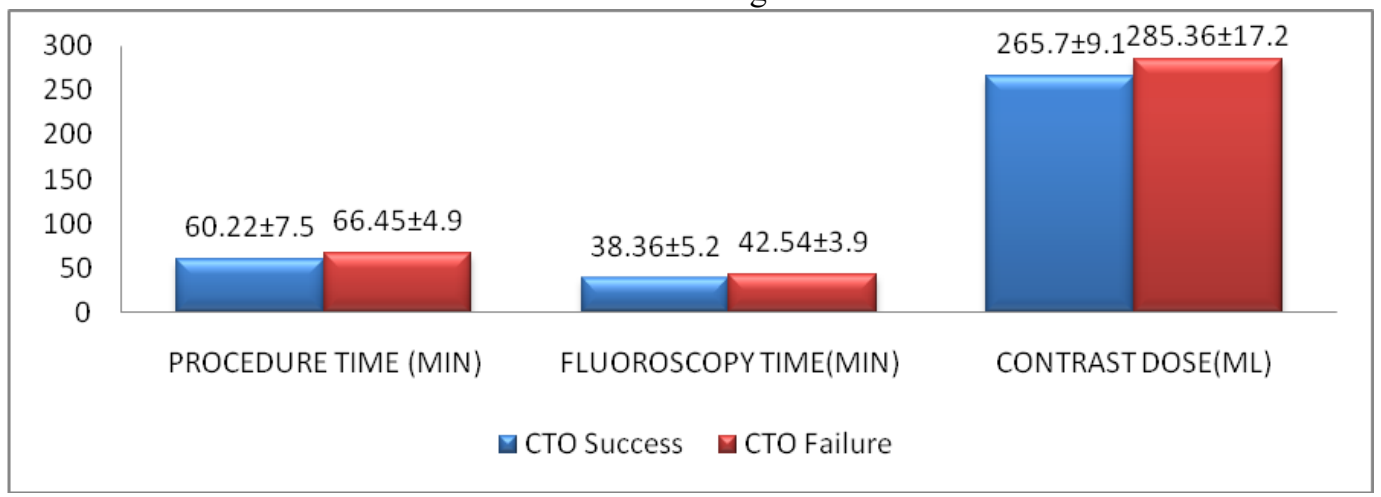

Figure 2: Procedural Characteristics - Procedure time, Fluoroscopy time and Contrast Used 


\section{International Journal of Science and Research (IJSR) \\ ISSN (Online): 2319-7064}

Index Copernicus Value (2013): 6.14 | Impact Factor (2014): 5.611

The CTO failure group had higher mean procedural time, fluoroscopy time and higher amount of contrast used during procedure compared to success group. Intracoronary medications used during procedure are shown in Figure 3.

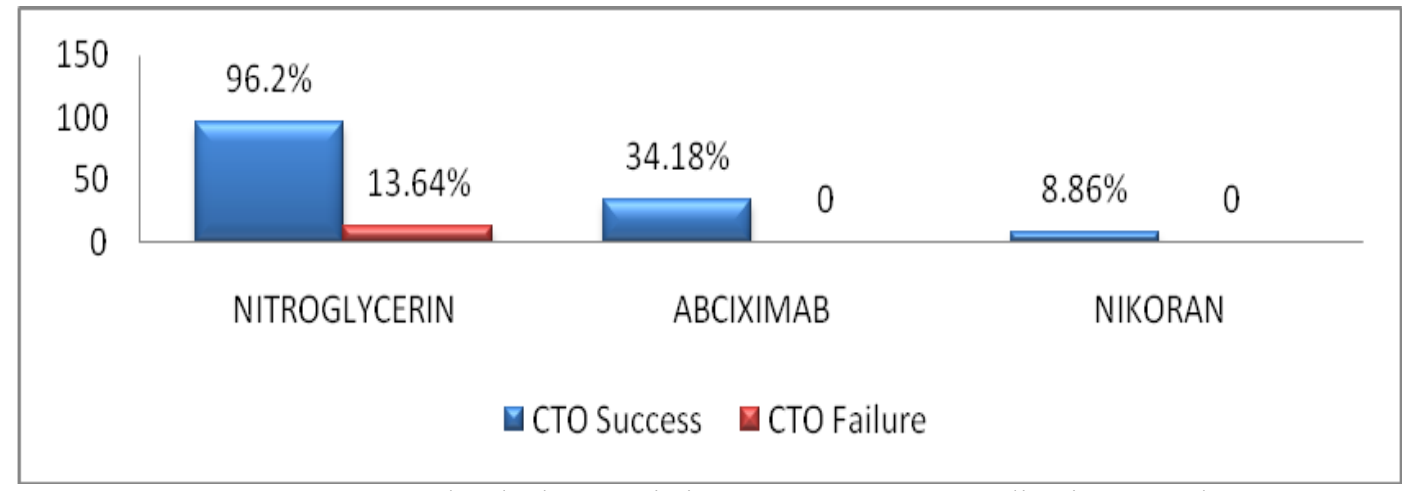

Figure 3: Procedural Characteristics - Intracoronary Medications Used

Glycoprotein II b / III a inhibitors (Abciximab) was used in $34.18 \%$ of patients in CTO success group. The complications are shown in Figure 4.

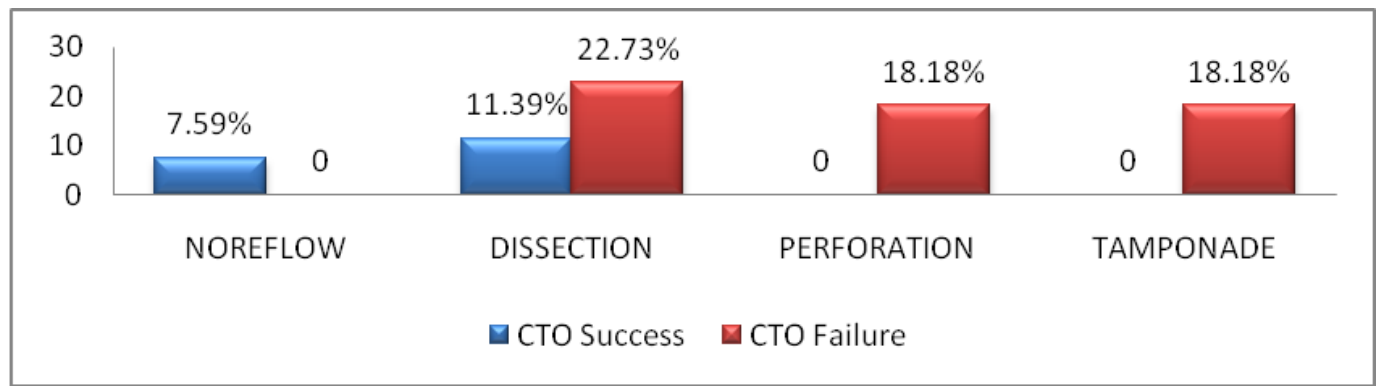

Figure 4: Procedural Characteristics - Complications

During the attempted PCI of CTOs, 5 patients $(22.73 \%)$ had dissection of the arterial wall in CTO failure group and 9 patients $(11.39 \%)$ in success group. In the CTO failure group, 4 patients $(18.18 \%)$ had coronary perforation and the PCI attempts were halted and emergency pericardiocentesis was done for cardiac tamponade. One patient required emergency surgery for perforation but developed hypotension, bradycardia and cardiac arrest during surgery. During the post procedure phase, 6 patients $(27.27 \%)$ in CTO failure group underwent CABG ( 3 required closure of peroration). No patient had stent thrombosis or MI in CTO success group. The in-hospital outcome for both CTO success and failure group are shown in Table 5.

Table 5: In hospital outcome

\begin{tabular}{|c|c|c|c|c|}
\hline Variable & $\begin{array}{c}\text { Total } \\
(n= \\
101)\end{array}$ & $\begin{array}{c}\text { CTO } \\
\text { Success } \\
(n=79)\end{array}$ & $\begin{array}{c}\text { CTO } \\
\text { Failure } \\
(n=22)\end{array}$ & P Value \\
\hline In-Hospital MACE & $7(6.93)$ & $0(0.00)$ & $7(31.82)$ & $0.000^{* *}$ \\
\hline Cardiac Death & $1(0.99)$ & $0(0.00)$ & $1(4.55)$ & $0.218^{\text {NS }}$ \\
\hline MI & $0(0.00)$ & $0(0.00)$ & $0(0.00)$ & NA \\
\hline $\begin{array}{c}\text { In-Hospital Stent } \\
\text { Thrombosis }\end{array}$ & $0(0.00)$ & $0(0.00)$ & $0(0.00)$ & NA \\
\hline Urgent Revascularization & $6(5.94)$ & $0(0.00)$ & $6(27.27)$ & $0.000^{* *}$ \\
\hline TVR-PCI & $0(0.00)$ & $0(0.00)$ & $0(0.00)$ & NA \\
\hline TVR-CABG & $6(5.94)$ & $0(0.00)$ & $6(27.27)$ & $0.000^{* *}$ \\
\hline
\end{tabular}

Data listed as number of patients (percent of group).

The CTO failure group had significantly higher rate of inhospital MACE compared to success group. The one year follow-up outcome for both CTO success and failure group are shown in Table 6.

Table 6: One Year Outcome

\begin{tabular}{|l|l|l|l|l|}
\hline \multicolumn{1}{|c|}{ Variable } & \multicolumn{1}{|c|}{ Total } \\
$(n=100)$ & $\begin{array}{c}\text { CTO } \\
\text { Success } \\
(n=79)\end{array}$ & $\begin{array}{c}\text { CTO } \\
\text { Failure } \\
(n=21)\end{array}$ & P Value \\
\hline 1 Year MACE & $28(28.00)$ & $15(18.99)$ & $12(57.14)$ & $0.000^{* *}$ \\
\hline Cardiac Death & $1(1.00)$ & $0(0.00)$ & $1(4.76)$ & $0.2100^{\mathrm{NS}}$ \\
\hline Non cardiac Death & $0(0.00)$ & $0(0.00)$ & $0(0.00)$ & $\mathrm{NA}$ \\
\hline MI & $9(9.00)$ & $5(6.33)$ & $4(19.05)$ & $0.089^{\mathrm{NS}}$ \\
\hline Revascularization & $17(17.00)$ & $10(12.66)$ & $7(33.33)$ & $0.045^{*}$ \\
\hline TVR-PCI & $3(3.00)$ & $3(3.80)$ & $0(0.00)$ & $1.000^{\mathrm{NS}}$ \\
\hline TLR-PCI & $5(5.00)$ & $5(6.33)$ & $0(0.00)$ & $0.581^{\mathrm{NS}}$ \\
\hline TVR-CABG & $9(9.00)$ & $2(2.53)$ & $7(33.33)$ & $0.002^{* *}$ \\
\hline
\end{tabular}

Data listed as number of patients (percent of group).

The CTO failure group had significantly higher rate of 1 year follow-up MACE, especially revascularization compared to success group. In the CTO failure group, 4 patients (19.05\%) had Non Q AWMI , one patient died as patient presented with $\mathrm{VT} / \mathrm{VF}$ and 7 patients $(33.33 \%)$ underwent $\mathrm{CABG}$. In the CTO success group, 5 patients $(6.33 \%)$ had Non Q AWMI, 3 patients $(3.8 \%)$ underwent TVR- PCI, 5 patients (6.33\%) TLR-PCI and 2 patients $(2.53 \%) \mathrm{CABG}$.

\section{Discussion}

In this study, we compared procedural, in-hospital and 1 year follow-up outcome in 79 successful and 22 failed CTO-

\section{Volume 4 Issue 11, November 2015}




\section{International Journal of Science and Research (IJSR) \\ ISSN (Online): 2319-7064}

Index Copernicus Value (2013): 6.14 | Impact Factor (2014): 5.611

PCI patients. Patients with failed CTO-PCI compared to successful group had higher incidence of DM, history of prior MI, smoking, multivessel involvement, had higher procedural complications, in-hospital and 1 year MACE rates.

The clinical outcome was significantly improved with lower in-hospital and 1 year MACE rates with successful CTO recanalisation. The Need for revascularization at 1 year follow up was significantly higher in CTO failure group.

In our study, procedural success rate is $78.21 \%$ which is higher than previous studies by Hoye et al. ${ }^{9}$ and Olivari et al. ${ }^{11}$ with rates of $65.1 \%$ and $73.3 \%$ respectively. Both these studies used 4 weeks duration to define CTO compared to $>3$ months duration in our study. The high success rate in our study is due to use of newer dedicated CTO guide wires, better back support ( microcatheter and balloon support) and increased operators experience. The predominant reason for lower success rates is failure to cross the lesion with a guide wire. In our study, failure to cross the lesion $(81.82 \%)$ and perforation $(18.18 \%)$ were the main reasons for failure.

In our study, success rate was higher in LAD (56.96\%) than RCA $(35.44 \%)$ and $\operatorname{LCX}(7.59 \%)$. Safley et al. ${ }^{15}$ reported higher success rate for LAD (77\%) than LCX $(76 \%)$ and $\operatorname{RCA}(72 \%)$. More recently, Hasegawa et al. ${ }^{16}$ reported higher success rates in LCX (79.0\%) than LAD (74.8) and RCA (71.8\%).

Presence of bridging collaterals which reflect chronicity of the lesions are associated with lower success rates. In our study, $36.36 \%$ of patients in CTO failure group had bridging collaterals. Han YL et al. ${ }^{17}$ reported lower success rates with presence of bridging collaterals whereas Kinoshita et al. $^{18}$ reported modest adverse impact of bridging collaterals.

The Success of CTO-PCI has significantly improved with the use of dedicated CTO guide wires and guide support. In our study, fielder XT guide wire $(34.18 \%)$ was most successful in crossing the CTO followed by whisper $(20.25 \%)$ and conquest pro wire $(18.99 \%)$ supported by microcatheter $(54.43 \%)$ and balloon $(40.51 \%)$. In our study, the mean procedure time, fluoroscopy time and the amount of contrast used was significantly higher in CTO failure group compared to success group. This could be due to higher complexity of CTO cases. Suzuki et al. ${ }^{19}$ reported higher mean procedure and fluoroscopy times for CTO than non CTO-PCI.

In our study, overall in-hospital MACE rate in all CTO patients was $6.93 \%$, which was higher than previous studies by olivari et al. ${ }^{11}$ Hoye et al. ${ }^{9}$ and rathore et al. ${ }^{20}$ with rates of $5.1 \%, 3.5 \%$ and $1.9 \%$ respectively. The in-hospital MACE rate was significantly higher in CTO failure group compared to success group. Chen et al. ${ }^{21}$ and Hoye et al. ${ }^{9}$ reported higher MACE rates in the CTO failure group very similar to our study. During the 1 year follow-up, CTO failure group was associated with a significantly higher MACE rates especially revascularization. Olivari et al. ${ }^{11}$ reported higher incidence of cardiac death, combined rate of cardiac death and MI and CABG in CTO failure group very similar to our study. This excess of cardiac death and MI in patients with failed CTO-PCI has been reported in the other studies but it has never been reported as early as at 1 year and these findings need to confirmed during longer followup. The CTO success group was associated with significantly lower MACE rates at 1 year follow up. Olivari et al. ${ }^{11}$ reported reduced 12 month incidence of cardiac death or $\mathrm{MI}$, a reduced need for $\mathrm{CABG}$ and freedom from angina in CTO success group very similar to our study.

Study limitations: It was single centre study. The results of this study could be influenced by selection criteria, operator experience and technique variation among operators. IVUS was not used due to in-availability at our centre during the study period.

\section{Conclusion}

A successful PCI of CTOs was associated with better one year follow-up outcome with lower incidence of death, MI and need of CABG compared to failed CTO-PCI

\section{References}

[1] Christofferson RD, Lehmann KG, Martin GV, Every N, Caldwell JH, Kapadia SR. Effect of chronic total coronary occlusion on treatment strategy. Am J Cardiol 2005;95:1088-91.

[2] Kahn JK. Angiographic suitability for catheter revascularization of total coronary occlusions in patients from a community hospital setting. Am Heart J 1993;126:561-4.

[3] Bell MR, Berger PB, Menke KK, Holmes DR. Balloon angioplasty of chronic total coronary artery occlusions: what does it cost in radiation exposure, time, and materials? Cathet Cardiovasc Diagn 1992;25:10-5.

[4] Puma JA, Sketch MH, Tcheng JE, et al. Percutaneous revascularization of chronic coronary occlusions: an overview. J Am Coll Cardiol 1995;26:1-11.

[5] Laarman G, Plante' S, de Feyter PJ. PTCA of chronically occluded coronary arteries. Am Heart J 1990;119:1153-60.

[6] Stone GW, Kandzari DE, Mehran R, et al. Percutaneous recanalization of chronically occluded coronary arteries: a consensus document: part I. Circulation. 2005; 112:2364-2372.

[7] Suero JA, Marso SP, Jones PG, et al. Procedural outcomes and long-term survival among patients undergoing percutaneous coronary intervention of a chronic total occlusion in native coronary arteries: a 20-year experience. J Am Coll Cardiol. 2001;38:409414.

[8] Ramanathan K, Gao M, Nogareda GJ, et al. Successful percutaneous recanalization of a non-acute occluded coronary artery predicts clinical outcomes and survival. Circulation. 2001;104:II-415. Abstract.

[9] Hoye A, Van Domburgh RT, Sonnenschein K, Serruys PW. Percutaneous coronary intervention for chronic total occlusions: a Thoraxcentre experience 19922002. Eur Heart J 2005;26:2630-6.

[10] Prasad A, Rihal CS, Lennon RJ, Wiste HJ, Singh M, Holmes DR Jr. Trends in outcomes after percutaneous coronary intervention of chronic total occlusions: a 25 


\section{International Journal of Science and Research (IJSR) \\ ISSN (Online): 2319-7064}

Index Copernicus Value (2013): 6.14 | Impact Factor (2014): 5.611

year experience from Mayo clinic. J Am Coll Cardiol 2007;49:1611-8.

[11] Olivari Z, Rubartelli P, Pisicone F, et al.on behalf of TOAST-GISE Investigators. Immediate results and one-year clinical outcome after percutaneous coronary interventions in chronic total occlusions (TOASTGISSE). J Am Coll Cardiol 2003;41:1672-8.

[12] Cutlip DE, Windecker S, Mehran R, et al. Clinical end points in coronary stent trials-a case for standard definitions. Circulation.2007;115:2344-51.

[13] Wijns W, Kolh P, Danchin N, et al. Guidelines on myocardial revascularization. The Task Force on Myocardial Revascularization of the European Society of Cardiology (ESC) and the European Association for Cardio-Thoracic Surgery (EACTS). Eur Heart J. 2010; 31:2501-55.

[14] Levine GN, Bates ER, Blankenship JC, et al. 2011 ACCF/AHA/ SCAI Guideline for Percutaneous Coronary Intervention: A report of the American College of Cardiology Foundation/American Heart Association Task Force on Practice Guidelines and the Society for Cardiovascular Angiography and Interventions. Circulation. 2011; 124(23):e574-651.

[15] Safley DM, House JA, Marso SP, Grantham JA, Rutherford BD. Improvement in survival following successful percutaneous coronary intervention of coronary chronic total occlusions: variability by target vessel. JACC Cardiovasc Interv. 2008;1(3):295-302.

[16] Hasegawa T, Godino C, Basavarajaiah S, et al. Differences in the clinical and angiographic characteristics of chronic total occlusion lesions in the three major coronary arteries. J Interv Cardiol. 2014 Feb;27(1):44-9.

[17] Han YL, Wang SL, Jing QM, et al. Percutaneous coronary intervention for chronic total occlusion in 1263 patients: a single-center report. Chinese Medical Journal [2006, 119(14):1165-1170].

[18] Kinoshita I, Katoh O, Nariyama J, et al. Coronary angioplasty of chronic total occlusions with bridging collateral vessels: immediate and follow-up outcome from a large single-center experience. J Am Coll Cardiol. 1995; 26:409-415.

[19] Suzuki S, Furui S, Kohtake H, et al. Radiation exposure to patient's skin during percutaneous coronary intervention for various lesions, including chronic total occlusion. Circ J 2006;70:44-8.

[20] Rathore S, Matsuo H, Terashima M, et al. Procedural and in-hospital outcomes after percutaneous coronary intervention for chronic total occlusions of coronary arteries 2002 to 2008: impact of novel guidewire techniques. JACC Cardiovasc Interv. 2009; 2:489-497.

[21] Chen SL, Ye F, Zhang JJ, et al. Clinical outcomes of percutaneous coronary intervention for chronic total occlusion lesions in remote hospitals without on-site surgical support. Chin Med J (Engl). 2009; 122(19):2278-2285.

\section{Author Profile}

Dr Suresh V Patted MD, DM, FACC, FAPSIC, FCSI Professor and HOD, Department of Cardiology, J.N.Medical college, Belgaum, Karnataka, India-590001.
Dr Prabhu C Halkati MD,DM,FACC,FAPSIC,FCSI Professor, Department of Cardiology, J.N.Medical college, Belgaum , Karnataka, India-590001.

Dr Vishwanath Hesarur, Senior Resident Department of Cardiology, J.N.Medical college, Belgaum , Karnataka, India590001.

Dr Sanjay C Porwal MD, DNB (cardiology),FAPSIC,FSCA,FACC Associate Professor , Department of Cardiology, J.N.Medical college, Belgaum , Karnataka,India-590001.

Dr Sameer Ambar MD,DM Associate Professor, Department of Cardiology, J.N.Medical college, Belgaum , Karnataka, India590001.

Dr.Ameet.Sattur MD,DM,Assistant Prof, Department of Cardiology, J.N.Medical college, Belgaum , Karnataka, India590001 